\title{
A Curious Mixture of Passion and Reserve": Understanding the Etic/Emic Distinction
}

Christina Hahn, Jane Jorgenson and Wendy Leeds-Hurwitz

\section{(2) OpenEdition \\ 12 Journals}

\section{Electronic version}

URL: http://journals.openedition.org/educationdidactique/1167

DOI: 10.4000/educationdidactique. 1167

ISSN: $2111-4838$

Publisher

Presses universitaires de Rennes

\section{Printed version}

Date of publication: 30 December 2011

Number of pages: $145-154$

ISBN: 978-2-7535-1832-2

ISSN: 1956-3485

\section{Electronic reference}

Christina Hahn, Jane Jorgenson and Wendy Leeds-Hurwitz, «A Curious Mixture of Passion and Reserve": Understanding the Etic/Emic Distinction », Éducation et didactique [Online], 5-3 | 2011, Online since 30 December 2013, connection on 09 December 2020. URL : http://journals.openedition.org/ educationdidactique/1167; DOI : https://doi.org/10.4000/educationdidactique.1167

This text was automatically generated on 9 December 2020 .

Tous droits réservés 


\title{
A Curious Mixture of Passion and Reserve": Understanding the Etic/ Emic Distinction
}

\author{
Christina Hahn, Jane Jorgenson and Wendy Leeds-Hurwitz
}

1 The title of this chapter alludes to the complex requirements placed on ethnographic researchers who maintain multiple roles as both insiders and outsiders to the social settings they study. When in the role of insiders, researchers try to apprehend the contextualized meanings of people's experiences within specific locales, while in their role as outsiders, they seek to identify commonalities across different locales. Clyde Kluckhohn alluded to this tension when he proposed that «the hallmark of the good anthropologist must be a curious mixture of passion and reserve » (1957, pp. 776-777). He implies that an ethnographer must become involved in the lives of those studied (the passion) and yet at the same time be able to step back in order to analyze what is being learned (the reserve).

2 The concepts of etic and emic, coined more than fifty years ago by the linguist Kenneth Pike in his work associated with the Summer Institute of Linguistics $(1954,1967,1982)$ presuppose these elements. An etic concept is one defined by the investigator independently of any particular context, and which can therefore serve as a basis for comparisons across cultures. An emic concept is grounded in the worldview of the participants, reconstructed by the researcher, and corresponds to the meanings participants themselves attach to their experience. Many disciplines concerned with human experience and behavior have incorporated both within their terminology and research procedures. However, debate over their use shows diverse and sometimes conflicting concepts of the terms (Hahn, 2005, 2006; Headland, Pike, \& Harris, 1990). They are often mentioned in passing, with little or no attention to their original use or meanings, and there has been substantial slippage between what Pike originally intended and how these terms are now used. Our goal here is to demonstrate the value of these terms to current research ; to do this, we will explain the abstract terms emic and etic ; then link them to a second, more concrete, pair of concepts, ethnography and 
ethnology ; finally, we will use a case study to demonstrate how to apply the terms to actual communication behavior. The case study illustrates how these dual perspectives provide a procedural framework for the study of children's everyday lives, and in particular, for the study of children's contributions to household work. For adults who are attempting to shed light on children's experiences, the interplay between etic and emic standpoints can be a vital resource. In the absence of an emic awareness, adult researchers run the risk of distorting what children are saying by filtering their accounts through our researcher (etic) lenses (Mayall, 2000). At the same time, etically derived concepts (in this case, " work » and « knowledge work ») are valuable insofar as they afford possibilities for transcending established ways of looking at children's daily lives. Through a dialectical process of etic/emic analysis, we are able to move beyond the stereotype of the child as a «time-consuming object» (Daly, 1996) who passively receives the care and resources of adults so that we begin to see children as active contributors to family life.

\section{Emic/etic}

We begin with a brief historical explanation of what Pike intended with his original conceptualization of emic and etic standpoints before returning to how they are used today. The concepts of emic and etic originated within linguistics, specifically phonemic and phonetic analysis, therefore the explanation logically begins with linguistics, phonemics and phonetics. Briefly, linguistics is the scientific study of language, and how people use language. Phonemics and phonetics are two parts of linguistics; phonemics is the description of the set of sounds that are meaningful within a single language, while phonetics is the description of all sounds that can be distinguished in any language.

Pike and other field linguists at the Summer Institute of Linguistics (now SIL International) worked closely with Wycliffe Bible Translators (now Wycliffe International) to develop written alphabets (written versions of speech) for languages existing only in spoken form. Both grew out the same circle of students involved in mission and in linguistique by 1942 . Wycliffe's goal was to create alphabets so that the Bible could be translated into new languages (http://www.wycliffe.org/about/ ourhistory.aspx). SIL developed a larger concern for sustainable literacy programs integrating formal and informal education in vernacular languages, including subjects such as nutrition, farming, health as well as the Bible (http://www.sil.org.sil). Kenneth Pike, a missionary as well as a linguist, served as President of SIL from 1942 to 1979 (http://www.sil.org/klp/) and coordinated the linguistics training. The terms phonemic and phonetic were already in wide use by linguists; they are not his creations. As he describes the transition from phonemic to emic, and phonetic to etic :

I took the word phonemic, crossed out the phon- part meaning "sound", and generalized my use of the new emic term to represent any unit of culture, at any level, of any kind, which was reacted to as a relevant unit by the native actors in that behavior. In the same way, I created the word etic from phonetic.

(Pike, 1998, pp. 154-155)

5 As one example, consider the articulation of the English «wh"; pronounced as in the word, « when. » The sound is very similar to that produced when blowing out a candle. In an unknown language, the linguist needs to find out if the heard or recorded sound is part of that language or just a sound that someone makes in other contexts or for 
other purposes like blowing out a candle. The linguist cannot make this decision by the precise description of the sound alone, but needs to consider context and situation and all the other vocal sounds in that language. In other words, language served as the model for the relationship between two things, that which conveys meaning within a specific context, and that which makes sense when taken out of context. A second example would be the word "paper " in English. The spelling of the written word suggests that the two " $\mathrm{p}$ " $\mathrm{s}$ sound the same. But when they are spoken, they are slightly different: the second " $\mathrm{p}$ » is aspirated (the exploding sound of the " $\mathrm{p}$ » is followed by an audible exhalation of breath). Both sounds are treated by native English speakers as $" p$ » and "carry" this meaning for them. So, phonetically they are different (because they are actually sounds that can be differentiated) but phonemically they are the same (because they do not convey different meaning to English speakers, who give both sounds the same name).

Despite the fact that there are two terms (etic/emic), there are actually three stages in the analysis. A linguist, or more generally, any researcher, begins with knowledge of a phenomenon, whether it is language or something else (and it can be anything, once the move from phonemic/phonetic to emic/etic is made), understanding how that phenomenon appears in at least one culture, the researcher's own, but more often, with a sense of the range of phenomena across several cultures. That's the first etic stage, or etic-1. Then, the researcher investigates a new culture, documenting the phenomenon in that one, working out a complete description of it within that context. That's the emic. Then, the researcher compares what was learned in that context with what is known of other contexts, other cultures, returning to the etic level, or etic-2, revising it based on what was learned in the new culture. This works in the same way for cultures, sub-cultures, domains, classrooms, communities of practice, etc., because the issue is the inside/outside dichotomy, not the size or purpose of the group.

Etic and emic were invented in the context of research on unknown and new linguistic phenomena, which initially convey no meaning to the investigator (this is because words spoken in a language convey no meaning to someone who does not understand that particular language). It is possible, and an obvious beginning point, to record the sounds people make that the researcher can hear, even before it is clear whether this is the complete and relevant set of sounds that native speakers of the language would name. Extra-linguistic phenomena, like other types of behavior, play a role in this approach insofar as they help to elicit the meanings of words. ${ }^{1}$ In line with his linguistic project, Pike's goal was to create an emic analysis of his data; that is, he wanted to understand which set of sounds conveyed specific meanings to native speakers of a language. However, initially he started with an etic analysis, only gradually moving to an emic analysis of the data (as everyone must).

8 Etic and emic perspectives and their respective approaches to the data actually contain 6 characteristics (Hahn, 2005, 2006). The etic approach is a nonstructural analysis concerned with (1) universals that may be described with some sort of (2) physical component eventually organized in some form of (3) typology (for language, this typology is the International Phonetic Alphabet, or IPA; typologies of other phenomena take the IPA as the model). When applying such a typology, the perspective is that of (4) an observation external to the system being investigated. Pike's utilization of the etic analysis describes both (5) the quality of initial field data as well as (6) the 
variants of an emic unit, like allophones, which are the variants of a phoneme described in etic terms (Quine, 1990).

The emic approach involves a structural analysis concerned with (1) the structural and contrastive system of one particular culture and language consisting of (2) distinctive contrastive units (3), implicitly or explicitly perceived as appropriate by native participants. It traces (4) an interpretation of the particulars within the system on system level, usually including (5) a physical feature within the emic unit, which is part of the different variants and relates to the initial description. By making such connections, the emic approach allows for an (6) interrelation of relativism and universalism (Hahn, 2005 ; Pike, 1988). Based on his experience Pike defines the emic unit as « a physical or mental item or system treated by insiders as relevant to their system of behavior as the same emic unit in spite of etic variability $(1990$, p. 28). Besides explicit or implicit attribution of appropriateness of occurrence in context, emic units may include subsets of other emic units. Native participants treat those units implicitly as emic, although sometimes they do have names for the particular emic units. Insofar as units are treated differently, they comprise contrastive features that elicit such different perceptions, usages or unconscious reactions by the native participants.

Researchers across many disciplines commonly define etic and emic as ends of a dichotomy, implying that they are two clearly distinct elements. The most common interpretations of this dichotomy include the following sets of opposites : essentials vs. concrete realizations, functional perspective vs. physical perspective, indigenous definitions vs. external criteria, theoretical vs. observational, culture-specific vs. universal, participant's perspective vs. researcher's perspective, verbal vs. nonverbal, mental vs. behavioral, interview vs. observation, subjective knowledge vs. objective knowledge, good vs. bad, ideal behavior vs. actual behavior, description vs. theory, private vs. public, ethnographic (idiosyncratically incomparable) vs. ethnological (cross-culturally comparable), soft facts vs. hard facts, informal procedure vs. formal procedure, and insiders vs. outsiders (Hahn, 2005 ; Headland et al., 1990). This list is probably not exhaustive. One implication of viewing these terms as a dichotomy leads some researchers to suggest that it is possible to perform either an emic or an etic analysis, rather than understanding that they are rather two different perspectives on the same behavior that should be used alternately; they were never intended to stand alone and so are inadequate when used in that way. Different information is gained from each form of analysis. For example, Marvin Harris (1985) discusses why members of two religions (Judaism and Islam) do not eat pork. The emic explanation is that the pig is an unclean animal, and so members of these groups develop a distaste for the meat, and religious obedience is perpetuated. ${ }^{2}$ The etic analysis points out that both of these religions developed among nomads in deserts, where it is not economic to raise pigs because they compete with humans for similar sources of food. Both are valid, but they are different ; jointly they provide a more complete picture.

11 We might then ask : What are the core characteristics of etic and emic in contemporary research? First of all, they draw attention to the importance of the perspective a researcher takes on data. As etic and emic are both operations performed by an observer, they describe something about the relationship between the observer and the subject of investigation. As soon as one refrains from equating etic and emic with other popular dichotomies, they become complementary ways to approach data (not 
alternatives), available for use in a procedural, even dialectical way. Etic and emic approaches resulting in etic and emic descriptions are both legitimate aims of research. Depending on these aims, the different procedural steps and their respective methods receive different amounts of attention during the research process. Often the criteria applied to produce the etic or emic description have perceptible, behavioral, and sometimes even extra-cultural features. This allows the etic perspective to be the starting point of analysis. The scientific observer of an unknown phenomenon has inevitably no other option than to begin with an etic analysis, regardless of whether or not he or she ultimately pursues an emic analysis. But the criteria employed and the analytic elements produced have a different structure on the system level, which the observer investigates. On this level, the emic units can be described according to their appropriateness. But both etic and emic analysis result in second-order constructs (Schutz, 1973). The appropriateness is not judged by the native participants, but reconstructed by the analyst, because the relevance structure (Schutz, 1973) of the emic system of the participants is not necessarily conscious. This establishes both etic and emic as observer operations. It is not only the emic perspective that needs the etic perspective at some point during analysis; the reverse is true also. In order to control for completeness and appropriateness of an etic typology, the researcher needs to rely upon preceding emic analysis. ${ }^{3}$

\section{Ethnography/Ethnology}

12 One application of the concepts of etic and emic is to the methods of ethnography and ethnology. In this section that parallel will be drawn out. Comparable with Pike's proposal of etic and emic, ethnography has two major components : the description of ethnographic facts, and the development of general propositions about human behavior. Although both of these are often subsumed under the single word ethnography, the second really is a separate step, formally termed ethnology.

Dell Hymes $(1955,1964,1969,1974)$ discusses the value of Pike's concepts, applies Pike's approach to his sociolinguistic and anthropological research, and integrates etic and emic into his own research program, the ethnography of communication. Hymes (1990) stays very close to Pike's proposed concepts in his interpretation, carefully reconstructing their quality as methodological perspectives. In his view, the terms describe the different relations between the scientific observer and the thing that is being studied. Hymes describes the dialectic as follows :

Pike's formulation has three terms, or moments, not two. It distinguishes operationally among (a) a frame of reference with which an observer of analysis approaches the data; (b) discovery of valid relation internal to what is being studied; and (c) reconsideration of the initial frame of reference in the light of the new results. (Hymes, 1990, p. 121)

Besides stressing the complementary and procedural character of the etic/emic distinction, Hymes also differentiates between the emic and insider's (or native's) view. He points out that the equation of emic with "native point of view» is misleading (1970, p. 281) because

As formulated by Pike on the basis of PHONEMIC, the notion does not imply that those whose behavior manifests an emic system are conscious of its nature or can formulate it for the investigator... Emic analysis is not good, etic analysis bad, but rather, there is an interdependence. (Hymes, pp. 281-282, emphasis in original) 

phonemic analysis, because phonemes are used but cannot be identified by the untrained native speaker (thus pointing to the distinction between being able to do something within a culture competently, and being able to describe it accurately). ${ }^{4}$

For Hymes as for Pike, for ethnographers as for other scholars who endeavor to understand human behavior, the first step is etic. The researcher begins by having a sense of the range of behavior across multiple cultures. No one enters a culture blind, without presuppositions of what is possible, and so although it seems logical to begin with an emic analysis, that comes second rather than first. ${ }^{5}$ An ethnography is primarily descriptive ; that is, it contains a description of the behaviors of a particular group of people in a particular time and place. ${ }^{6}$ But ethnology is primarily theoretical : it involves comparing the descriptions of behavior across multiple groups, as a result learning something about the range of what is possible. ${ }^{7}$

, the ethnographer begins with a sense of what occurs across several cultures or groups (etic-1), and then begins to document one (often a new) culture or group in detail (emic). But after that description is reasonably complete, it is important to match it with other detailed descriptions of specific cultures or groups, thus moving to the level of comparison again (etic-2). Both levels include description as well as analysis; the distinction is between an effort to adequately describe a single culture or group, versus using multiple descriptions of individual cultures or groups in order to adequately describe a pattern, not between description and analysis. The complete pattern may not actually occur in any one culture or group, but it adequately describes what occurs when behavior in multiple cultures or groups is taken into account. As Hymes points out, there are thus two different types of etic analysis performed: "the initial framework that gives one a purchase on the system " and "the systematic comparison of the results of emic analyses » $(1970$, p. 282).

What may not yet be sufficiently clear is that the ethnographer moves frequently and consistently between these three stages in order to do good work; they are not attempted in chronological order, and one is not completed before beginning the next. Before entering the field to examine some particular topic, some general sense of the range of possibilities related to that topic should be acquired (usually through reading descriptions of multiple cultures or groups similar to the one to be studied). Once in the field, descriptions of behavior are prepared, but they are modified as a result of knowing what prior descriptions, whether of this group or others, have shown. Once the period of ethnography, involving intense study, observation, and description is ended, the researcher moves back into the stage of ethnology, matching the description of this one group with descriptions of others, and checking for what might have been missed initially when the focus was circumscribed. This is one reason why doing ethnographic research well takes time. A good researcher will move between these three stages multiple times in any one study, stopping to consider what other groups do, and returning to the specific group in question to ask further questions that arise as a result of comparison with other cultures and their assumptions.

These stages : etic-1 or initial ethnology (analysis of what is already known), emic or ethnography (description of something new), and etic-2 or later ethnology (re-analysis in light of what has been learned by the addition of the new to the existing corpus), are thus not steps one chooses from, but rather stages through which all research must pass. ${ }^{8}$ Description of something new is always preceded by some understanding of what

Éducation et didactique, 5-3 | 201 
has already been documented (by other researchers, or by the same researcher at an earlier time). And analysis of past and present data must always be changed to take new data into account.

Conklin tells us "the problems of ethnography are in the largest sense those of translation. Eventually all observations must be 'translated'into the ethnographer's descriptive code» (1968, p. 172). Ethnographers do not invent what they write from nothing; they work to interpret what they discover in light of what socially created meanings it has for the participants. They then work to translate this meaning from one group of people to another. Ethnographers, whether in anthropology, communication, or education, thus have no choice but to accept the job of translator. With luck, this metaphor will help researchers remember that both etic and emic explanations are translations, or interpretations, provided by the researcher; neither is in fact a direct statement by the group being studied.

\section{Exemplar}

21 The following example shows how an emic/etic analysis might be used ethnographically to connect specific instances of cultural behavior to macro-level phenomena. The example is drawn from research on the interrelationships between children's lives, family life, and recent trends in teleworking and other forms of flexible work. In this project, Jorgenson (2006; Jorgenson \& Sullivan, 2009) has been seeking to understand the work contributions made by children whose households are, increasingly, becoming sites in which parents make use of new technologies to perform a portion of their paid work.

The cross-cultural literature suggests that work is an important and salient element in children's lives. In many parts of the world and in some segments of the U.S. population, children's paid work is an economic necessity for families (Levison, 2000 ; Miller, 2005). Yet as an etic concept, "work» does not map directly onto the experiences of middle and upper-middle class children, especially in the U. S. and in other postindustrial economies where the semantic notions of "childhood" and «work» are seen as incompatible. In such settings, childhood is constructed as a time of play and study, free of adult-like responsibilities, and children who must work from an early age for pay are often described as having «lost» or "missed» their childhoods (Levison, 2000). Although middle-class children may be expected to perform household chores, these activities are framed mainly as preparation for adulthood rather than as intrinsically valuable to the household (and ironically, parents'supervision of children's household chores is considered part of the « work » of childrearing that parents are expected to do (Daly, 1996). Of particular interest in this research project was how these taken-for-granted images of children as the passive recipients of others'care - rather than as active contributors to family life - might serve to obscure the ways in which "work» meanings and identities are relevant to their lives.

To achieve some conceptual clarity about the forms and meanings of children's household contributions, Jorgenson used an emic approach. She gave middle-school children disposable cameras to record their perspectives on home life and then used the photographs as the basis for interviews with each child about his or her daily routines and responsibilities. She found that children do not necessarily experience a 
work/play dichotomy. Rather, they play while working and work while playing (Thorne, 1987), illustrated by a boy who walks his dog while roller-blading, or by a brother and sister who invent a game for unloading the dishwasher. Many of children's seemingly useful activities in the family sphere like watching younger siblings, preparing a snack or meal, or assisting family members with technology, do not necessarily count as « work » to them or their family members.

Whereas the chores formally assigned to children tend to be simple, routine tasks like making beds and taking out trash, the sharing of technological expertise involves a much more complex set of skills. The photographs and interviews revealed that children possess a broad store of knowledge about technology, including the ability to help parents prepare PowerPoint presentations, get rid of "pop-ups, " attach photographs to email, and type for family members who lack keyboarding skills. In many cases, such help is instrumental to parents'accomplishment of their paid work. Jorgenson was also struck by the taken-for-granted way in which these helping episodes take place, as children respond to parents'requests in the moment rather than putting them off until later. To the extent that these interactions are taken as "natural» and second-nature, they are reminiscent of the behavior of parents and children working side by side in family businesses. Song (1996) found that children who work in ethnic family restaurants speak colloquially about « helping out » as opposed to simply "working, " in the sense that « helping out » implies for them a willingness to contribute one's labor for the long-term benefit of the family as distinct from « working » for an impersonal employer for wages.

With this move from the emic framework to etic-2, activities that would normally remain invisible come into focus as significant contributions to the mutuality of family life and to the general caring of the household. From an etic-2 perspective, we might even construe parent-child interactions as instances of «knowledge work » in their resemblance to recent organizational trends toward network-based work processes that promote flexibility over hierarchy. Professional knowledge workers are encouraged to seek out multiple sources of information for problem solving rather than to rely on traditional lines of authority (Fine, 2005). Conceptualizing parent-child collaborations as a form of knowledge work illustrates how a "childhood-alien " concept (Qvortrup, 2000) drawn from a separate area of analysis outside of the family realm can be useful in transcending established ways of looking at parent-child interactions. The dialectical relationship between etic and emic frameworks offers an awareness of the interconnected nature of different forms of work, adults'paid work and children's unpaid work, that link public and private spheres in the New Economy.

\section{Conclusion}

Understanding Pike's goals in developing the concepts of etic and emic brings us to a more sophisticated and complex understanding of them; we lose the easy dichotomy, but gain a strong analytic tool. When using etic and emic as concepts in research, these core characteristics offer some orientation about how to apply them productively. (1) Etic and emic describe the relationship between the observer and the data. (2) They signify different approaches with different, yet complementary, methods. (3) To employ them in procedural ways is more productive than as a dichotomy. (4) Etic and emic approaches resulting in etic and emic descriptions are both legitimate aims of 
research. (5) The etic analysis uses external criteria, which qualifies it as a starting point. (6) The emic analysis is a reconstruction of the often unconscious emic system of the subject(s) involved. (7) Etic and emic approaches complement each other by controlling and improving the conceptualizations and operationalizations conjoined with each perspective.

Some researchers treat etic and emic as a dichotomy, assuming it is possible to perform either an emic or an etic analysis. The point of this chapter has been to emphasize instead that these are two different perspectives on the same behavior that should be used as alternating ways of understanding. The concepts were never intended to stand alone. Different information is gained from each form of analysis, so using both in alternation leads to a more nuanced understanding of human behavior, as well as encouraging the consideration of behavior in more than a single culture at a time.

\section{BIBLIOGRAPHY}

Campbell, D.T. (1988). Qualitative knowing in action research. In E.S. Overman (Ed.), Methodology and epistemology for social science: Selected papers (pp. 360-376). Chicago : University of Chicago Press.

Conklin, H.C. (1968). Ethnography. International Encyclopedia of the Social Sciences, 172-178.

Daly, K. (1996). Families \& time : Keeping pace in a hurried culture. Thousand Oaks, CA : Sage.

Douglas, M. (1966). Purity and danger : An analysis of concepts of pollution and taboo. New York : Praeger.

Fine, M. (2005). Individualization, risk and the body : Sociology and care. Journal of Sociology, 41 (3), 247-266

Glaser, B.G., \& Strauss, A.L. (1967). The discovery of grounded theory: Strategies for qualitative research. Hawthorne, NY : Aldine.

Hahn C. (2005). Innensichten. Aussensichten. Einsichten : Eine rekonstruktion der emic-etic-debatte. Aachen : Shaker.

Hahn, C. (2006). Clear-cut concepts vs. methodological ritual : Etic and emic revisited. Beiträge zur Geschichte der Sprachwissenschaft, 16, 245-262

Hahn, C (2008) : Fieldwork 101 : Ethnographic construction of Seattle's Scanhouse. In A. Eschbach, M.A. Halawa \& H. Loenhoff (Eds.), Audiatur et altera pars. Kommunikationswissenschaft zwischen historiographie, theorie und empirischer forschung : Festschrift für H. Walter Schmitz (pp. 366 - 381). Aachen : Shaker.

Hall, B. (2005). Among cultures: The challenges of communication ( $2^{\text {nd }}$ ed.). Belmont, CA : Thompson Wadsworth.

Harris, M. (1985). Good to eat : Riddles of food and culture. New York: Simon and Schuster.

Headland, T.N., Pike, K.L., \& Harris, M. (1990). Emics and etics : The insider/outsider debate. Newbury Park, CA : Sage. 
Hymes, D. (1955). Review of Language in relation to a unified theory of the structure of human behavior. American Sociological Review, 20, 512.

Hymes, D. (Ed.). (1964). Language in culture and society. A reader in linguistics and anthropology. New York : Harper \& Row.

Hymes, D. (1969). Review of language in relation to a unified theory of the structure of human behavior. American Anthropologist, 71, 361-363.

Hymes, D. (1970). Linguistic method in ethnography : Its development in the United States. In P. Garvin (Ed.), Method and theory in linguistics (pp. 249-325). The Hague : Mouton.

Hymes, D. (1974). Foundations in sociolinguistics : An ethnographic approach. Philadelphia : University of Pennsylvania Press.

Hymes, D. (1990). Emics, etics, and openness : An ecumenical approach. In T.N. Headland, K.L. Pike, \& M. Harris (Eds.), Emics and etics : The insider/outsider debate (pp. 120-126). Newbury Park, CA : Sage.

Jorgenson, J. (2006). Children as IT experts. Paper presented to the National Communication Association, San Antonio, TX, Nov. 16-19 $9^{\text {th }}, 2006$.

Jorgenson, J. \& Sullivan, T. (2009). Accessing children's perspectives through participatory photo interviews. Forum Qualitative Sozialforschung/Forum : Qualitative Social Research, 11 (1), Art. 8, http:// nbn-resolving.de/urn:nbn:de:0114-fqs100189.

Keating, E. (2001). The ethnography of communication. In P. Atkinson, A. Coffey, S. Delamont, J. Lofland, \& L. Lofland (Eds.), Handbook of ethnography (pp. 285-301). London : Sage.

Kluckhohn, C. (1957). Developments in the field of anthropology in the $20^{\text {th }}$ century. Journal of World History, 3, 754-777.

Leeds-Hurwitz, W. (1986). The ethnologic endeavor. Paper presented to the Speech Communication Association, Chicago, IL, November 13-16, 1986.

Leeds-Hurwitz, W. (1988). «A curious mixture of passion and reserve » : The doing of ethnography. Paper presented to the Speech Communication Association, New Orleans, LA, November 3-6, 1988.

Leeds-Hurwitz, W. (2004). Ethnography. In K. Fitch \& R. Sanders (Eds.), Handbook of language and social interaction (pp. 327-353). Mahwah, NJ : Lawrence Erlbaum Associates.

Levison, D. (2000). Children as economic agents. Feminist Economics, 6 (1), 125-134

Mayall. B. (2000). Conversations with children : Working with generational issues. In P. Christensen \& A. James (Eds.), Research with children : Perspectives and practices (pp. 120-135). London : Falmer Press.

Miller, P. (2005). Useful and priceless children in contemporary welfare states. Social Politics, 12 (1), 3-41.

Philipsen, G. (1994). Ethnography of speaking. In R.E. Asher (Ed.), The encyclopedia of language and linguistics (pp. 1156-1160). Oxford : Pergamon Press.

Pike, K.L. (1954). Language in relation to a unified theory of the structure of human behavior. Part I. (Preliminary ed.). Glendale, CA : The Summer Institute of Linguistics.

Pike, K.L. (1967). Language in relation to a unified theory of the structure of human behavior (2nd ed). The Hague : Mouton. 
Pike, K.L. (1982). Linguistic concepts : An introduction to tagmemics. Lincoln : University of Nebraska Press.

Pike, K.L. (1988). Cultural relativism in relation to constraints on world view - an emic perspective. Bulletin of the Institute of History and Philology, 59, 385-399.

Pike, K. L. (1990). Pike's Reply to Harris. In T.N. Headland, K.L. Pike, \& M. Harris (Eds.), Emics and etics : The insider/outsider debate (pp. 62-74). Newbury Park, CA : Sage.

Pike, K.L. (1998). A linguistic pilgrimage. In E.F.K. Koerner (Ed.), First person singular III :

Autobiographies by North American scholars in the language sciences (pp. 145-158). Amsterdam : John Benjamins.

Quine, W.V.O. (1990). The phonem's long shadow. In T.N. Headland, K.L. Pike, \& M. Harris (Eds.), Emics and etics: The insider/outsider debate (pp. 164-167). Newbury Park, CA : Sage.

Qvortrup, J. (2000). Macroanalysis of childhood. In P. Christensen \& A. James (Eds.), Research with children : Perspectives and practices (pp. 77-97). London : Falmer Press.

Sapir, E. (1925). Sound patterns in language. Language, 1, 37-51.

Schutz, A. (1973). Common-sense and scientific interpretation of human action. In A. Schutz, Collected papers, vol. 1 : The problem of social reality (pp. 3-47). The Hague : Martinus Nijhoff.

Song, M. (1996). « Helping out » : Children's labour participation in Chinese take-away businesses in Britain. In J. Brannen \& M. O'Brien (Eds.), Children in families : Research and policy. London : Falmer Press.

Thorne, B. (1987). Re-visioning women and social change : Where are the children ? Gender \& Society, 1, 85-109.

\section{NOTES}

1. In his extensive work over more than 4 decades, Pike develops conceptual variations of the etic/emic distinction. This paper cannot reflect this conceptual development; instead it focuses on the more consistent aspects of Pike's definitions and applications as well as on Pike's summary in his later work (Hahn, 2005 ; Pike 1990).

2. See Douglas (1966) for further discussion and the classic analysis of why particular foods are avoided.

3. Just as the linguist needs to check whether a vocal sound is a phon or not when constructing the phonetic alphabet (Sapir, 1925).

4. Hymes not only clarifies the meaning of the terms coined by Pike, he also investigates language, nonverbal behavior and social interaction. He analyzes them as systematically integrated, and culturally formed and structured in each speech community, by deploying etic and emic concepts (Hymes, 1969, 1974 ; see also Keating, 2001; Philipsen, 1994). This scope goes beyond Pike's illustrative examples of behavioral sequences, which helps to elicit the structure of a language and co-founds many research programs dealing with communication, language and social interaction that move beyond classic linguistic approaches.

5. For this reason, comparison of differing norms was actually the first step taken chronologically (Leeds-Hurwitz, 2004), although it shortly became evident that complete documentation of each culture was essential prior to comparison. 
6. One micro example would be the ethnographic construction of one student community in Hymes'notion of speech community: Seattle's «Scanhouse " (Hahn, 2008).

7. As Glaser and Strauss (1967) point out, it not only is possible, but desirable, to discover theory from data; as Campbell (1988, p. 372) points out, "all knowing is comparative. »

8. Hall's brief discussion of etic and emic comes down on the same side by arguing that using the etic/emic distinction to describe two types of research « distorts the value of Pike's work » (2005, p. 69).

\section{ABSTRACTS}

The terms "etic" and "emic" are often mentioned in passing, with little or no attention to their original use or meanings, and there has been substantial slippage between what Kenneth Pike originally intended and how these terms are now used. Our goal here is to demonstrate the value of these terms to current research; to do this, we will explain the abstract terms emic and etic; then link them to a second, more concrete, pair of concepts, ethnography and ethnology; finally, we will use a case study to demonstrate how to apply the terms to actual communication behavior. The case study illustrates how these dual perspectives provide a procedural framework for the study of children's everyday lives, and in particular, for the study of children's contributions to household work. Understanding Pike's goals in developing the concepts of etic and emic brings us to a more sophisticated and complex understanding of them; we lose the easy dichotomy, but gain a strong analytic tool.

\section{INDEX}

Keywords: etic, emic, ethnography, ethnology, knowledge work, parent-child interactions, work-play dichotomy

\section{AUTHORS}

\section{CHRISTINA HAHN}

(Department of Communication Sciences, University of Duisburg-Essen)

\section{JANE JORGENSON}

(Department of Communication, University of South Florida)

\section{WENDY LEEDS-HURWITZ}

(Department of Communication, University of Wisconsin-Parkside) 